BULLETIN Bulletin hispanique

HispaniQuE Université Michel de Montaigne Bordeaux

109-1 | 2007

Varia

\title{
Non ay tales maestras como estas viejas troyas ( Libro de Buen Amor, 699c y 937c)
}

Juan Casas Rigall

\section{CpenEdition}

Journals

Édition électronique

URL : http://journals.openedition.org/bulletinhispanique/62

DOI : 10.4000/bulletinhispanique.62

ISSN : 1775-3821

Éditeur

Presses universitaires de Bordeaux

Édition imprimée

Date de publication : 1 juin 2007

Pagination : 7-16

ISBN : 978-2-85276-094-3

ISSN : 0007-4640

Référence électronique

Juan Casas Rigall, « Non ay tales maestras como estas viejas troyas (Libro de Buen Amor, 699c y 937c) », Bulletin hispanique [En ligne], 109-1 | 2007, mis en ligne le 17 mai 2017, consulté le 20 avril 2019. URL : http://journals.openedition.org/bulletinhispanique/62 ; DOI : 10.4000/

bulletinhispanique.62 


\title{
«Non ay tales maestras como estas viejas troyas» (Libro de Buen Amor, 699c y 937c)
}

\author{
Juan Casas Rigall \\ Universidade de Santiago de Compostela
}

Chercheurs et éditeurs du Libro de Buen Amor discutent l'interprétation du mot troya(s), attribué à Trotaconventos et aux entremetteuses (699c et 937c), et peutêtre à une serrana (972b). Après une évaluation de ces théories, l'auteur présente une nouvelle hypothèse: comprendre troya comme un jeu de mots dilogique, avec les sens 'sale, immorale, putain' et 'machine militaire, catapulte'.

Estudiosos y editores del Libro de Buen Amor discrepan en la interpretación de la palabra troya(s), atribuida a Trotaconventos y las alcahuetas (699c y 937c), y tal vez a una serrana (972b). Tras una evaluación de estas distintas teorias, se propone una nueva hipótesis: entender troya como un juego de palabras dilógico, con las acepciones 'sucia, inmoral, puta' y 'máquina bélica, catapulta'.

Writers on and editors of the Libro de Buen Amor disagree about the meaning of the word troya(s), used to describe Trotaconventos and other bawds (699c and 937c), and perhaps a serrana (972b). After examining these different theories, I propose a new hypothesis that suggests that troya contains a double meaning: on the one hand, 'dirty, immoral, whore' and, on the other, 'war machine, catapult.

Mots-clés : Juan Ruiz - Libro de Buen Amor - Lexicographie - Critique textuelle.

1. En su benemérita edición del Libro de Buen Amor, ya Tomás Antonio Sánchez reparó en el curioso término troya(s), que se refiere a las alcahuetas en los vv. 669c y 937c, y a una serrana en el v. 972b. Pese a la temprana BHi, Tome 109, n 1 - juin 2007 - p. 7 à 16. 
atención recibida por el vocablo, los últimos editores del poema declaran todavía la inseguridad de su interpretación. Es propósito del presente trabajo el examen de las distintas propuestas sobre el caso, cuyo colofón será una nueva hipótesis.

Los dos primeros pasajes, de formulación semejante, se predican de Trotaconventos y su oficio de celestina:

[Texto de $S$ (variante G); om. T]

Era vieja buhona (bohona $G$ ) destas (delas $G$ ) que venden joyas estas echan el laço estas cavan las foyas non ay tales maestras como estas viejas troyas estas dan la maçada sy as orejas oyas (699).

[Texto de $S$; om. GT]

ffizose corredera delas que benden joyas ya vos dixe que estas paran cauas $\&$ foyas non ay tales maestras como estas vieja[s] troyas estas dan la maçada si as orejas oyas (937).

En la tercera y última documentación, el calificativo se atribuye a la Chata sólo en el ms. G:

[Texto de $S$ (variante $G$ ); om. T]

Despues (luego despues $G$ ) desta ventura (venta $G$ ) fuy me para ssegouja non acomprar (para comprar $G$ ) las joyas para la chata nouja (troya $G$ ) fuy ver (veer $G$ ) vna costilla (costiella $G$ ) dela serpiente groya que mato al viejo rrando segund dize en moya (maya $G)(972)^{1}$.

Considerado el orden cronológico, las distintas explicaciones propuestas se pueden reunir en cinco grupos:

a) Alforja'.- Es la interpretación de Sánchez, que entiende troyas como un calificativo metafórico referido a la alcahueta -para la Chata, en su edición prefiere la lectura novia-. Como la forma más común en la lengua medieval es troxa, Sánchez postula la posibilidad de una ligera errata en los manuscritos, idea que se mantiene en la reedición al cuidado de Ochoa y en el texto incluido en la Biblioteca de Autores Españoles².

1. Cito por las ediciones facsimilares de los tres manuscritos: $G$ (Madrid, 1974), $S$ (Madrid-Salamanca, 1975) y $T$ (Madrid, 1977). Desarrollo abreviaturas.

2. Véase T. A. Sánchez, ed., Colección de poesias castellanas anteriores al siglo XV. Tomo IV. Poesías del Arcipreste de Hita, Madrid, 1790, p. 330; la reedición de E. de Ochoa, Paris, 1842; y Poetas castellanos anteriores al siglo XV, en P. J. Pidal y F. Janer, eds., Biblioteca de Autores Españoles, 57, Madrid, 1864. 
b) Alusión metafórica a la ciudad de Troya.- Tal línea, dominante hasta mediados del s. XX, es compartida por editores como Cejador y lexicógrafos como Aguado y Richardson. Con todo, los matices interpretativos son varios; así, Cejador ve en Troya un "símbolo de guerra y destrucción», correlativo al maçada del verso siguiente. Más común es, no obstante, entender la alusión a la antigua ciudad en referencia a los muchos años de la vieja; por esta vía, Boggs et alii llegan a proponer 'mujeres arrugadas' 3

c) 'Cerda, cochina, sucia, puta'.- Es la tesis de Carlos Clavería, plenamente aceptada por Giorgio Chiarini ${ }^{4}$. La idea desarrolla una propuesta etimológica de Friedrich Diez, quien destaca formas análogas en la Romania -it. troia, fr. truie, prov. trueia-troia y, en el iberorromance, el cat. truja-con la acepción de 'hembra del cerdo'. El étimo es una forma troia del latín tardío, que Diez hace provenir del porcus trojanus mencionado por Macrobio (Saturnalia, III, 13), la receta culinaria de un cerdo relleno inspirada en el caballo de Troya (vid. infra apdo. 3). A partir de este sentido básico, troia evoluciona a la acepción figurada de 'sucia, puta' -documentada en italiano-, cambio semántico paralelo al caso de voces castellanas como guarra. Con renovados argumentos, Daniel Devoto defiende también esta propuesta: el término troya y otras denominaciones de la cerda están bien documentados en Iberoamérica para designar juegos infantiles ${ }^{5}$.

d) Troya (s), errata por croya(s).- En su edición del poema, Joan Corominas propone la conjetura croya (s) 'ruines, malas, viciosas', a partir del céltico crodios, cuya acepción -ciertamente próxima al troyas de Clavería- resulta adecuada a todos los contextos del Libro de Buen Amor. Entre los editores posteriores, esta propuesta es aceptada por Raymond S. Willis y Marcella Ciceri ${ }^{6}$.

e) Apelativo despectivo de sentido y origen inciertos.- La mayoría de los últimos editores del poema -así, Joset, Jauralde, Blecua, Cañas, Gybbon-

3. Véase J. Cejador, ed., Libro de Buen Amor, Madrid, 1913, vol. 2, p. 245 nota; J. M. Aguado, Glosario sobre Juan Ruiz, poeta castellano del siglo XIV, Madrid, 1929, s. v. troya; H. B. Richardson, An Etymological Vocabulary to the Libro de Buen Amor of Juan Ruiz, Arcipreste de Hita, New Haven, 1930, s. v. troya; y R. Boggs et alii, Tentative Dictionary of Medieval Spanish, Chapel Hill, 1946, s. v. troya.

4. Véase C. Clavería, "Libro de Buen Amor, 699c: 'estas viejas troyas'", Nueva Revista de Filología Hispánica, 2, 1948, p. 268-272; y Giorgio Chiarini, ed., Libro de Buen Amor, Milano-Napoli, 1964, p. 134.

5. Véase D. Devoto, "Troyo-troya», Boletin de la Real Academia Española, 52, 1972, p. 319-332.

6. Véase J. Corominas, ed., Madrid, 1967, p. 266-270; R. S. Willis, ed., Princeton, 1972, p. 189, 251 y 261; y M. Ciceri, ed., Modena, 2002, p. 174, 221 y 230. 
Monypenny, y Pereira y Zahareas- comparten tanto la forma troya(s), que no enmiendan, como las dudas acerca de su acepción -en todo caso, peyorativa- y raíz etimológica precisas ${ }^{7}$.

2. No todas estas hipótesis alcanzan el mismo grado de plausibilidad.

La propuesta de Sánchez, descartada tempranamente, no es sin embargo la teoría más endeble. Para empezar, la forma troya en el sentido de 'alforja' se documenta en algún otro testimonio antiguo, si bien es muy posible que la grafía $\langle y\rangle$ resulte aquí de una confusión paleográfica con $\langle x\rangle$, relativamente habitual ${ }^{8}$. De suponer que en el original del Libro de Buen Amor se leía troxas, estaríamos ante un caso de asonancia, admisible en el sistema métrico de Juan Ruiz. Sin embargo, como la voz troxa aparece en otro pasaje del poema -v. $711 \mathrm{~d}$ del ms. $S$, lectura preferible a la trivialización siella de $G$, en una cuaderna que $T$ omite-, resulta improbable que un copista haya incurrido después repetidamente en el error troyas por troxas.

En cuanto al sentido del vocablo, si ponemos en relación troyas 'alforjas' con los imaginativos nombres de la alcahueta en las estrofas 924 a 927, el apelativo no parece descabellado en sentido metafórico. No hay en aquella serie ninguna denominación estrechamente afín a nuestra voz ${ }^{9}$, pero, por el material de la alforja -la piel animal-, podría relacionarse con el latín scortum 'cuero' y, de ahí, 'prostituta', ligazón semántica que también se manifiesta en el español pelleja y en otras voces ibéricas y románicas ${ }^{10}$. Así entendido, la descalificación moral del término sería atribuible tanto a Trotaconventos como a la Chata. No obstante, este argumento, muy forzado en sí mismo, resulta más descartable al considerar que troya(s) está fuera del contexto marcadamente figurado de las cuadernas 924-927.

7. Véase J. Joset, ed., Madrid, 1974, vol. 1, p. 253 nota y 1990, p. 322 nota; P. Jauralde, Madrid, 1981 y 1988, p. 244 nota; A. Blecua, ed., Barcelona, 1983, p. 109 nota y Madrid, 1992, p. 521 nota; J. Cañas, 1984, p. 158 nota; G. B. Gybbon-Monypenny, ed., Madrid, 1988, p. 505 nota; y O. Pereira y A. Zahareas, eds., Madrid, 1994, p. 424, quienes no comentan el término en su Itinerario del Libro del Arcipreste: glosas críticas al Libro de Buen Amor, Madison, 1990.

8. «(...) allí do estauan los parientes del duque $\&$ sus escuderos $\&$ su gente, armándose \& ensillando sus cauallos \& guisando sus troyas \& sus maletas (...)", Gran conquista de Ultramar, Salamanca, Giesser, 1503, fol. 38r; cito por ADMYTE II. Archivo digital de Manuscritos y Textos Españoles, Madrid, 1999 [CD-ROM], transcripción de A. Cortijo; aquí y en los sucesivos usos de esta fuente puntúo y acentúo a la moderna.

9. Cfr. J. K. Walsh, «The Names of the Bawd in the Libro de Buen Amor», en Florilegium Hispanicum. Medieval and Golden Age Studies Presented to Dorothy Clotelle Clarke, Madison, 1983, p. 151-164.

10. Véase J. Corominas, Diccionario Crítico Etimológico Castellano e Hispánico, con la colaboración de J. A. Pascual, Madrid, 1980-1991, s. v. piel. 
La hipótesis que domina hasta mediados del s. XX -una alusión a Troya como emblema de la destrucción o, más bien, la decrepitud- resulta poco convincente. El problema radica, antes que en la atribución de la nota a Trotaconventos -ya un tanto fantasiosa-, en sus vínculos con la Chata, hombruna y fea, mas no vieja. Es cierto que, frente a $G$, en $S$ se lee nouja, pero, de acuerdo con los principales editores del poema (Chiarini, Corominas, Joset, Jauralde, Blecua o Gybbon-Monypenny), la variante de $S$ resulta claramente trivial. Si acaso, la interpretación concreta de Cejador, que se centra más en Troya como exemplum bélico-destructivo, sería también aplicable a la agresiva serrana, por lo cual, a falta de otra más plausible, resulta la hipótesis menos desatinada dentro del conjunto que asocia troyas a la ciudad de Troya.

Pero, sin duda, la idea de Clavería es, con diferencia, la lectura más certera de todas las propuestas hasta la fecha: en la Romania más próxima -Francia, Provenza e Italia-, así como en Cataluña, se documentan los vocablos truietrueia-troia-truja, etimológicamente emparentados, que pertenecen a la misma familia del troya(s) de Juan Ruiz. De su acepción principal, 'cerda', es fácil derivar los sentidos figurados de 'sucia, inmoral, puta'-conocidos en italiano desde el s. XIV hasta hoy-, de acuerdo con la evolución semántica de otros vocablos análogos. Añadamos que el término, en su sentido primitivo, está bien documentado en textos mediolatinos bajo las formas troia, troga, truga, truia, trueia, truiga o truega ${ }^{11}$, conjunto en donde no falta el latín ibérico de ámbito oriental:

Mittere nos debeamus in monasterio Alahone (...) cum aliquid de nostra hereditate (...) terra (...) et uno cavallo de colore tilgo, et unum bove et XXIII oves et una troga, et nostra ferramenta ad laborandum (Documento ribagorzano de 874).

(...) somera una cum ipso apario, troia una, oves 9, agnos 5, dextrale una, tribano uno (Cartulari de S. Cugat, antes de 964) ${ }^{12}$.

En el dominio iberorromance, las primeras documentaciones catalanas datan del s. XIII, la más antigua de 1272.

Para rechazar la tesis de Clavería, Corominas manejó en su edición dos argumentos de desigual valor. Así, la afirmación de que troya 'sucia,

11. Véase J. F. Niermeyer, Mediae Latinitatis Lexicon Minus. Lexique latin médiévalfrançais/anglais, Leiden, 1976, s. v. troia.

12. Apud J. Corominas, Diccionari etimològic i complementari de la llengua catalana, con la colaboración de J. Gulsoy y M. Cahner, Barcelona, 1983, s. v. truja. 
inmoral, puta' no tiene sentido en su aplicación a la Chata resulta por completo inadmisible, pues, tanto por su estampa montaraz como por su actidud moral, la serrana merece tales atributos. Asevera también Corominas que la familia de troia 'cerda' "nunca existió fuera de los límites galorrománicos latu sensu», en donde se incluyen los ámbitos italiano y catalán. Con sus referencias a troya como denominación de juegos infantiles en la Iberoamérica contemporánea, Devoto ha puesto en tela de juicio esta afirmación. Pero, además, las reservas de Corominas están lastradas por un error de planteamiento muy frecuente en la evaluación de la lengua literaria: Corominas está identificando de manera impropia el idiolecto de Juan Ruiz con su registro poético. Esta perspectiva distorsionada oculta la realidad de un estilo tan variado, rico en evocaciones e influjos, como el arte verbal de Juan Ruiz, que escribe condicionado por su idiolecto pero también por sus lecturas. Por ello, si consideramos la importancia de las letras francesas en la conformación de la poesía de clerecía, no resultaría en absoluto extraño que un autor incorporase como término libresco un galicismo acaso ajeno a su habla. Como, además, el vocablo está bien documentado en textos ibéricos mediolatinos y catalanes, el problema del origen del troyas en el Libro de Buen Amor no es tal.

Por añadidura, la propuesta alternativa de Corominas -la conjetura croya(s) - es mucho menos consistente. Pese a que la forma troya (s) se lee con meridiana claridad tanto en $S$ como en $G-T$ omite todos los contextos que nos interesan-, Corominas se afana en destacar la fácil confusión paleográfica $\mathrm{de}\langle\mathrm{t}\rangle \mathrm{y}\langle\mathrm{c}\rangle$. Tras discutir con escasa convicción la realidad de alguna $<\mathrm{t}\rangle$ en estos pasajes, Corominas se acoge a la posibilidad de que el copista del arquetipo, por error, haya escrito troya(s) por croya (s). Pero, cuando trata de documentar el nuevo término, se encuentra con una distribución románica no muy distinta al caso de troia y sus herederos: del céltico crodios derivan formas francesas, provenzales, italianas y catalanas, a las cuales, sí, se suman resultados gallegos y portugueses, que, a juicio de Corominas, demuestran la continuidad ibérica de un término celtorrománico. Al margen del caso conjetural del Libro de Buen Amor, Corominas no localiza ningún otro ejemplo de croya (s) fuera de textos gallegos, portugueses y catalanes, aunque hoy es posible señalar al menos una muestra ${ }^{13}$. Lo más sorprendente, con

13. «Muchos d'éstos son a Dios sobre detractadores, mumuradores, mjcarosos \& escandaljzadores, exçesiuos, burladores, muy fuertes juradores de aquellas sus juras meljosas $\&$ suaves, avarientes de aver, ljsonjerosos a perder, ynfingidos en saber, fictos fabladores, vjndicatiuos, subplantadores, de abomjnables \& odiosos pecados cometedores. ¡O mjseros al esecutar, croyos a perdonar! (...)» (Alfonso Martínez de Toledo, Libro del Arcipreste de 
todo, es el distinto rasero aplicado ahora: si troya también deriva de un étimo céltico (vid infra apdo. 3), ¿por qué no considera Corominas las documentaciones del Libro de Buen Amor como prueba de que el término excedía el ámbito oriental ibérico?

Como se ha señalado, la fortuna de la conjetura de Corominas ha sido escasa entre los editores posteriores del poema. Por un comentario aislado de su Diccionario crítico etimológico castellano e hispánico, da la sensación de que el propio Corominas mitigó su rechazo de troyas y, con ello, la interpretación de Clavería: «es dudoso que troya, Juan Ruiz 699c, 937c, designara propiamente la puerca, como en otros romances» ${ }^{14}$. Si bien no se acepta aquí la lectura troyas, el escepticismo se expresa de modo más contenido. Paradójicamente, aunque croya(s) no sea enmienda aceptada por los editores más solventes, en los más recientes estudiosos del problema subyacen todavía ciertos planteamientos de Corominas: no se acepta su enmienda específica, pero se acata, en cambio, la autoridad etimológica del maestro. Sólo así se puede explicar que no se asuma la interpretación de Clavería, en conjunto atinada.

3. A continuación postulamos, no obstante, una lectura parcialmente distinta de troya en el Libro de Buen Amor, más compleja desde el punto de vista poético.

El primer intento de explicación etimológica de troia 'cerda' y sus derivados correspondió a Diez, quien, como hemos adelantado, relaciona el término con la historia troyana: Macrobio habla de un porcus troianus, la receta culinaria de un cerdo relleno trasunto del caballo de Troya:

Nam Titius in suasione legis Fanniae obicit saeculo suo quod porcum Troianum mensis inferant, quem illi ideo sic vocabant, quasi aliis inclusis animalibus gravidum, ut ille Troianus equus gravidus armatis fuit (Saturnalia, III, 13; olim II, 9) ${ }^{15}$.

Después, la supuesta evolución porcus Troianus $>$ porcus de Troia $>$ Troia daría origen a troia 'cerda'. Aunque esta propuesta pronto hizo fortuna y

Talavera, fol. 84r-v, en ADMYTE II, transcripción de E. Naylor). A propósito del Libro de Buen Amor, este pasaje había sido señalado ya por Devoto, «Troyo», y por Joset, en su edición de 1974, a partir del Corbacho de Mario Penna, quien, no por azar, editaba troyos; posteriores estampas del Arcipreste de Talavera prefieren, en cambio, croyos, la forma que se lee en el ms. escurialense h.III.10.

14. Véase Corominas, Diccionario, s. v. puerco.

15. J. Willis, ed., Ambrosii Theodosii Macrobii Satvrnalia, Leipzig, 1983, p. 195. 
aún se acepta en diccionarios etimológicos recientes ${ }^{16}$, es dudoso que el porcus troianus haya sido denominación usual de un alimento. Además, las variantes troga, truga, truia, trueia, truiga o truega en documentos latinos no pueden explicarse desde troia. Por ello, la hipótesis del porcus troianus ha sido firmemente contestada, entre nosotros por Corominas, quien piensa más bien en el céltico ${ }^{*}$ trogia, que en último término se remonta al indoeuropeo porkos 'cerdo', con influjo del irlandés medio trogaid 'ella pare, da a luz'. En sentido estricto, por tanto, aunque troia y sus formas emparentadas se documenten en textos mediolatinos -el más antiguo, el glosario de Kassel, del s. VIII-, no son éstas voces latinas, sino vocablos prerromanos conservados en la lengua de sustrato ${ }^{17}$.

Ahora bien, cabe destacar que tanto troia como sus correlatos francés e italiano comparten otra acepción, en apariencia inconexa respecto de 'cerda': una máquina bélica, en concreto, una especie de catapulta. La forma truie en este sentido se documenta en el francés del s. XIII y el italiano troia en el s. $\mathrm{XV}^{18}$. Con anterioridad, el término figuraba en diversos manuscritos de la Historia Karoli Magni et Rhotolandi del Pseudo Turpín (h. 1150), incluido el Codex Calixtinus, en una relación de artefactos de asalto a una fortaleza:

Septimo vero mense, aptatis iuxta murum petrariis et mangarellis et troiis et multonis ceterisque artificium ad capiendum (...) (Codex Calixtinus).

Septimo vero mense, aptatis iuxta murum petrariis et mangarellis et troiis et arietibus ceterisque artificiis ad capiendum castella (...) (Ms. A 6) ${ }^{19}$.

Du Cange recoge el anterior ejemplo y, con reservas, apunta una idea de Froissart, para quien troia es denominación de un tipo de catapulta que arroja grandes piedras y, además, consta de un parapeto para protección de hasta cien hombres ${ }^{20}$. Con prudencia, Meredith-Jones subraya la dificultad

16. Para los etimólogos inmediatamente posteriores a Diez, véase Clavería, "Libro de Buen Amor, 699c», p. 269. En cuanto a obras relativamente recientes, sostienen aún esta idea C. Battisti y G. Alessio, Dizionario etimologico italiano, Firenze, 1975, 5 vols, s. v. troia, o A. Julien Greimas, Dictionnaire de l'ancien français. Le Moyen Âge, Paris, 1979, s. v. truie.

17. Véase Corominas, Diccionari, s. v. truja.

18. Para el francés, véase Niermeyer, Lexicon, s.v. troia; y, para el italiano, Battiste y Alessio sizionario, s. v. troia.

19. Véase C. Meredith-Jones, ed., Historia Karoli Magni et Rhotolandi ou Chronique du Pseudo-Turpin, Paris, 1936 (reimpresión, Genève, 1972), p. 116-117.

20. Ch. Du Cange, Glossarium Mediae et Infimae Latinitatis, Paris, 1840-1850, s. v. troia. 
de identificar con precisión muchos ingenios bélicos medievales ${ }^{21}$. En este sentido, es posible que la segunda nota semántica de Froissart esté condicionada por los más que probables vínculos de esta troia 'catapulta' con -ahora sí- el caballo de Troya.

Aunque en latín clásico no se documente troia en este sentido, el término y la frase correlativa Troianus ludus se habilitaron para la designación de un juego ecuestre militar, instituido por Eneas para su hijo Ascanio y reestablecido por Augusto, que Nebrija vierte al castellano como 'escaramuça de niños' y 'juego de cañas' ${ }^{22}$. En consecuencia, en troia 'catapulta' acaso se produce un desplazamiento semántico similar, incluso más inmediato, que lleva desde el caballo de Troya -un ingenio bélico, a fin de cuentas- a una máquina de asedio $^{23}$.

De vuelta a las cuadernas 699 y 937 del Libro de Buen Amor, se advierten en la formulación de Juan Ruiz dos campos semánticos metafóricos estrechamente vinculados: las artes de la caza (echan el laço, 699c) y de la guerra (dan la maçada, 699d y 937d) permiten caracterizar las asechanzas de las alcahuetas. En cavan las foyas (699b) y, sobre todo, paran cauas e foyas (937b) se amalgaman ambas evocaciones, pues los dos lexemas reiterados comparten acepciones cinegéticas y militares: 'foso a modo de trampa para animales' al lado de 'zanja que rodea una fortificación, galería subterránea con materiales incendiarios o explosivos, o paso subterráneo' ${ }^{24}$.

21. Véase Meredith-Jones, ed, Historia Karoli Magni, p. 299-300.

22. Véase A. de Nebrija, Diccionario latino-español, en ADMYTEII, fol. 151v, s. v. Troia, transcripción de A. Cortijo, y Vocabulario español-latino, en ADMYTEII, fol. 60v, s. v. juego de cañas, transcripción de J. O’Neill y A. Cortijo. Como complemento, cfr. E. Forcellini, Lexicon totius Latinitatis, Padova, 1940, s. v. Troia. Habría que estudiar si el nombre de los juegos infantiles contemporáneos de que habla Devoto, «Troyo-troya», deriva de aquí o, como piensa este estudioso, de troya 'cerda'.

23. Téngase en cuenta, con todo, que el término latino sus 'cerdo' también se empleó para designar un ingenio bélico (Du Cange, Glossarium, s. v. sus), con lo cual es sinónimo perfecto de troia y, al lado de este otro término, constituye un dominio etimológico y semántico de tal complejidad que excede los propósitos de nuestro trabajo.

24. Así, «Tal es el diablo con sus asacamientos (...) para fazer entrar al mesquino del omne: así es la red para las aues e los anzuelos para los peçes, y los lazos y los foyos para las bestias» (Sancho IV, Castigos y documentos (BN, ms. 6559), fol. 5r, en ADMYTE II, transcripción de W. Palmer et alii); en sentido bélico, son más comunes las formas fonsario y fosado, de acuerdo con F. Gago-Jover, Vocabulario militar castellano (siglos XIII-XV), Granada, 2002, ss. vv. En cuanto cava, tiene también un sentido cinegético, como recuerda la traducción castellana de Bartholomaeus Anglicus: «Caua es assí llamada porque es cauada, ca no es otra cosa que tierra cauada por yngenio humano (...). E dize Sant Hierónimo (...) que el león es preso en semejantes cauas, ca dentro de vna caua ponen vna oveja al baxo e, quando la vey el león, 
Con Clavería, debe entenderse que la acepción de troyas 'sucias, inmorales, putas' se manifiesta en los contextos anteriores, así como en 972b, aquí en referencia a la Chata. Pero en los dos pasajes sobre Trotaconventos y las alcahuetas, troyas ostenta simultáneamente el sentido de 'máquinas de asalto, catapultas': se mantiene así la correlación de metáforas bélico-cinegéticas, que enlaza el verso c de ambas cuadernas con maçada 'golpe de maza' en el cierre de la estrofa, y entronca con otros términos militares previamente atribuidos a la alcahueta (maça 'maza', 924a, y avancuerda 'cuerda de ballesta', 925b).

Esta clase de usos dilógicos, casos extremos de silepsis en los que un mismo término presenta dos sentidos a un tiempo, son característica del estilo de Juan Ruiz: recordemos, por ejemplo, a los cuervos que devorarán al asno moribundo cras, cras -'graznido del cuervo' y 'mañana, mañana' (507d) - o el nombre de la serrana Cruz y el juego equívoco con la cruz cristiana (115-121).

Al igual que troya 'sucia, inmoral, puta', es cierto que troya 'catapulta' no se ha documentado en iberorromance fuera del probable caso del Libro de Buen Amor. En el dominio mediolatino, el testimonio del Codex Calixtinus, pese a su impronta hispánica en relación con el Camino de Santiago, no tiene fuerza suficiente para asegurar el arraigo ibérico del término. Por ello, conviene recordar de nuevo un argumento anterior: los registros literarios del poeta culto, lógicamente basados en su idiolecto, exceden la esfera de la lengua materna, al constituirse como amalgama en donde la formación del letrado, con sus lecturas, es capítulo fundamental.

deçiende por la tomar $\&$ después no puede salir; $\&$ después hazen los caçadores vna otra caua cabo aquella, do ellos ponen vna fuerte arca que se çierra presto $\&$ se abre a grand pena (...)» (V. de Burgos, El libro 'De propietatibus rerum', fol. 178v, en ADMYTE II, transcripción de $\mathrm{M}^{\mathrm{a}} \mathrm{J}$. García Toledano e I. Ma Galiano Sierra); pero las acepciones bélicas del término, varias y bien documentadas, son aun más frecuentes (véase Gago-Jover, Vocabulario militar, s. v. cava). 